\title{
O Colégio Agrícola de Francisco Beltrão/PR e os desafios da educação politécnica
}

\author{
Nara Tatiana Costa* \\ Clésio Acilino Antônio**
}

\begin{abstract}
Resumo
O artigo é resultado da pesquisa de Mestrado em Educação, UNIOESTE, Francisco Beltrão/PR, que discutiu os desafios da educação politécnica de um Colégio Agrícola, a partir de um Estudo de caso. Os objetivos foram compreender a educação politécnica para jovens do campo, caracterizar o projeto educativo de Ensino Médio e Profissional e analisar a relação trabalho e educação nas práticas pedagógicas. Como resultado, sistematizou e compreendeu a formação teórico-prática, na qual o ensino dos conhecimentos científicos apresentava-se associado à formação das capacidades técnicas. As considerações demarcam os princípios da politecnia como importante para um projeto educativo do trabalhador.

Palavras-chave: Educação politécnica; Colégio Agrícola; Práticas pedagógicas.
\end{abstract}

\section{The Agricultural College of Francisco Beltrão PR and the challenges of Polytechnic Education}

\begin{abstract}
This paper is a result of a Master research in Education at UNIOESTE, Francisco Beltrão (PR). It discussed the challenges of polytechnic education in an agricultural college by means of a case study. Its objectives were to comprehend the polytechnic education to the countryside youth, to characterize the educational project of High and Professional School and to analyze the relationship between work and education in educational practices. As a result, it systematized and understood the theory-practical training in which the teaching of scientific knowledge were presented related the technical capabilities training. Final considerations delimit principles of polytechnic as crucial to the worker educative project.

Keywords: Polytechnic Education; Agricultural College; Pedagogical practices.
\end{abstract}

\section{Introdução}

A educação de Ensino Médio e Profissional do Colégio Agrícola de Francisco Beltrão, Sudoeste do Paraná, associa estudo e trabalho. Os espaços extraclasse propiciam o contato com a sociedade e a realização de trabalho socialmente necessário. $\mathrm{O}$ regime de educação integral possibilita que os alunos permaneçam no Colégio no transcorrer da semana e, nos ambientes que caracterizam o internato, realizam a própria gestão das atividades necessárias para manter o espaço que utilizam.

São adolescentes do campo, filhos de trabalhadores, em sua maioria da agricultura familiar, que recebem uma educação profissionaltécnica, com aulas teóricas e práticas da Base Nacional Comum e também da Área Técnica. Nessa via, o objetivo principal da pesquisa foi analisar como os princípios da educação politécnica estavam presentes nas práticas pedagógicas do Colégio Agrícola de Francisco Beltrão.

Ampliar o universo humano sem fechar-se entre quatro paredes torna-se uma questão importante que se relaciona com o Colégio Agrícola e sua estrutura e organização educativa, diferente do

*Endereço Eletrônico: naratatianacosta@ gmail.com

***Endereço Eletrônico: clesioaa@hotmail.com que está posto na maioria das escolas. Além da estrutura física com laboratórios e espaços de produção, a Fazenda Escola e as práticas que se realizam em tais espaços, monitorias, grupo de estudos, estágios e visitas técnicas voltam-se para o vínculo entre o ensino e a realidade, educação e trabalho.

O Colégio Agrícola de Francisco Beltrão localiza-se numa área de 45ha na Linha Santa Bárbara, interior de Francisco Beltrão. Sua história é envolvente, significativa e relevante na educação no campo, no Sudoeste do Paraná, mas pouco conhecida até para seus profissionais, alunos e comunidade em geral. É uma história que se encontra registrada em partes desconexas no documento do Projeto Político-Pedagógico do Colégio e em outras formas de registros, como jornais, documentos e algumas produções de natureza acadêmica.

A educação que se propõe formar jovens para o campo não se encontra separada do sistema econômico e se revela, de certo modo predominante, para a agricultura industrializada. Não tem como pesquisar a educação que acontece num determinado espaço educativo sem discutir a 
realidade que a envolve. Ou seja, para pesquisar educação, politecnia e Colégio Agrícola, foi necessário abordar as contradições dessa educação e o contexto do campo que se apresenta aos jovens, ou ainda, a realidade social que os envolve cuja formação acontece sob um específico projeto educativo.

A partir desse contexto, as principais partes do presente artigo se compõem da reflexão acerca da educação que se propõe formar jovens para o campo, embasada nos princípios da educação politécnica. Traz algumas experiências escolares de educação politécnica e retrata as práticas pedagógicas do Colégio Agrícola. Por fim, as considerações apontam para diversas potencialidades educativas no Colégio Agrícola, remetendo-se às ações sociais de sua manutenção como instituição de Ensino Médio, às práticas que educam pelo trabalho e à organização coletiva, entre estas a organização para o estudo, aulas práticas, visitas técnicas, dias de campo agropecuários, projetos sociais especiais. Todas práticas que, aos poucos, envolvem e tornam os alunos capazes de auto-organização, fator que implica diretamente no processo de educação.

\section{Projeto Formativo de Ensino Médio e Profissional do Colégio Agrícola}

O Curso de Educação Profissional Técnico em Agropecuária e Ensino Médio Integrado tem duração de três anos e o Curso Subsequente duração de 1 ano e meio. No Curso Médio Integrado os alunos permanecem de forma integrada e integral no internato de segunda à sexta-feira, e nos finais de semana alguns pequenos grupos realizam plantões. No Curso Subsequente somente são cursadas as disciplinas da Área Técnica, com alunos externos que estudam e permanecem no Colégio somente durante os períodos matutino e vespertino, não sendo internos, pois já concluíram o Ensino Médio.

É importante observar como as particularidades de uma instituição educativa podem sugerir formas diferenciadas de educação. Assim, a discussão dessas particularidades educativas do Colégio Agrícola, também expressas por decretos ou normas, são capazes de reorganizar as instituições educacionais, propor novos formatos pedagógicos e estruturais, definir a formação dos profissionais e rever as matrizes curriculares.

Em se tratando de definição curricular, considera-se que esta não é apenas um procedimento técnico a prescrever de modo formal os componentes curriculares e posteriormente seus conteúdos. É importante compreender como o processo das definições curriculares, para o próprio formato do currículo, traz suas conexões com o processo histórico, o que permite revelar os caminhos sociais de sua implicação no que está posto no projeto curricular e formativo (GOODSON, 1995).

Os currículos dos Colégios Agrícolas estão relacionados diretamente à lógica da agricultura capitalista, que tem mais legitimidade social e é a que serve mais ao poder econômico. Contraditoriamente, o currículo pode ser praticado conforme o projeto educativo da instituição, como aquele amplamente discutido e definido com o coletivo de profissionais, o que possibilita-lhe ganhar outra dimensão, que não somente uma visão formal e adaptativa. Raramente os profissionais da educação percebem a importância da prática pedagógica influenciada pelas prescrições do currículo, configurada por vários contextos que pressupõem o cultural, o social e requer intencionalidade. É o que Sacristán (2000) define como prática pedagógica multicontextualizada.

O Plano de Curso Técnico Agropecuária Integrado (2011) do Colégio Agrícola se orienta pela Deliberação No 09/06-CEE/PR. Este Plano de Curso propõe que o Técnico em Agropecuária em formação será capacitado a: perceber de maneira sistêmica as implicações sociais, econômicas, ambientais, políticas e técnicas de sua atuação profissional; detectar os problemas e aplicar as soluções técnicas, de forma suficientemente criativa, sustentável, rápida e coerente com a realidade rural; atuar em sistemas de produção agropecuária e extrativista, fundamentados em princípios de desenvolvimento sustentável; planejar, executar, acompanhar e fiscalizar todas as fases dos projetos agropecuários; administrar propriedades rurais.

O Plano de Curso (2011) ainda se refere ao perfil do profissional Técnico em Agropecuária: que este seja capaz de aplicar e monitorar programas preventivos de sanitização na produção animal, vegetal e agroindustrial; fiscalizar produtos de origem vegetal, animal e agroindustrial; realizar medição, demarcação e levantamento topográficos rurais; atuar em programas de assistência técnica, extensão rural e pesquisa; ser tolerante e receptivo à diversidade cultural, étnica, religiosa, política e social das comunidades as quais vier a se inserir no mundo do trabalho.

Percebe-se que o Plano de Curso, em que 
estão contidas as Matrizes Curriculares, adota um discurso de visão sistêmica e sustentabilidade. Ao tornar o profissional sistêmico e o espaço rural sustentável sob a ótica do agronegócio, as ações voltadas para a degradação das riquezas naturais, sob o comando da economia globalizada, são resguardadas pelo discurso da sustentabilidade. Conforme Silva (2012, p. 208-209):

[...] o conceito oficial do desenvolvimento sustentável adotado por vários governos, políticos, empresários e mesmo por algumas organizações não governamentais (ONGs) implica a continuidade do processo de homogeneização cultural e ecológica, que hoje é mais do que nunca comandado pelo capital transnacional. Para esses poderosos atores do cenário mundial, não há contradição entre o processo de acumulação capitalista (e suas escandalosas desigualdades sociais e desastres ecológicos) e a perspectiva de sustentabilidade.

Ressalva importante a ser feita é que o termo sustentabilidade entrelaça todas as disciplinas da Matriz Curricular do Colégio Agrícola, ou seja, quando as disciplinas são apresentadas trazem em sua ementa o termo.

O Projeto Político-pedagógico do Colégio Agrícola (2012) aponta para o compromisso da Educação Profissional como Educação Básica, como direito social e condição indispensável para a superação do simples adestramento às adaptações e às demandas ditadas pelo mercado. Adotou uma concepção de escola unitária, que se coloca para os jovens como direito à conclusão da escolaridade em nível médio numa relação com o trabalho produtivo.

Segundo o PPP do Colégio, o homem, por meio do trabalho, constrói um mundo histórico e cultural ao apoderar-se do que lhe convém para sobreviver. Esse processo traz uma possibilidade imperativa para a humanidade: a passagem do conhecimento histórico de uma geração à outra. Há o reconhecimento no PPP que essa "passagem" não ocorre assim tão naturalmente, de forma passiva, linear; existem relações sociais que se chocam a todo o momento e promovem mudanças, transformações.

A divisão social do trabalho apresenta um ponto fundamental para discutir a educação para os trabalhadores. Por um rumo que trate dessa contradição, como aponta Ciavatta (2001), a escola, ao voltar-se para a clara percepção de mundo e buscar a emancipação dos alunos, pode lançar mão de um projeto educativo que dê condições ao esclarecimento da realidade vivida e responda qual a especificidade que assume o trabalho humano no contexto estrutural da sociedade.

Importante observar que vários professores do Colégio Agrícola já tiveram ou ainda têm algum tipo de vínculo com o Serviço Nacional de Aprendizagem Rural - SENAR, especialmente os chamados "instrutores"1. Assim, constatamos a influência dos professores instrutores na realização de práticas para uma educação empreendedora no Colégio Agrícola. Inclusive ocorrem Cursos do SENAR que são administrados no Colégio, como é o caso do Programa Empreendedor Rural ${ }^{2}$, geralmente voltados aos alunos do Curso Técnico Agropecuária e Agroindústria Subsequente, por terem, esses, maior idade.

Sob tal aspecto, o projeto de formação do Colégio e a prática dos profissionais expressam contradições de como esta se volta para o mercado de trabalho do agronegócio, a partir de uma formação unilateral. D'Agostini e Vendramini (2014) abordam a relação do empresariado com a educação do campo, e destacam os vínculos construídos com empresas multinacionais detentoras de tecnologias para o agronegócio, com a Monsanto. Para eles, esta é uma empresa que em tese se "preocupa" com a educação do campo, com o ambiente e com a sustentabilidade. O discurso da preocupação na verdade disfarça a real preocupação que é com o treinamento, formação empreendedora do jovem no campo e com a liquidez de seus lucros a partir da continuidade do consumo dos venenos, sementes e produtos que a empresa vende aos agricultores.

Fica evidente o desafio do Colégio Agrícola em lidar criticamente com os professores e alunos acerca de uma educação de raízes empreendedoras, que, em tese, seria mais atrativa, interessante, de fácil aceitação por parte de todos, para, em contrapartida, construir um conceito e prática de educação voltados para a formação emancipadora.

Como consta, o Colégio Agrícola também propicia aos alunos uma formação técnica, além dos componentes do currículo da Base Nacional Comum. Então, o que há de fundamento nesse tipo de formação que regularmente acontece no Colégio Agrícola?

Tende-se a confundir educação técnica como tecnicista. Souza (2008) discute que a educação técnica historicamente teve prejuízos ao ser entendida como uma educação tecnicista e não ser reconhecida como capaz de aliar o trabalho manual e intelectual, a teoria à prática. Para o autor, 
vale assinalar a pouca relevância que têm os saberes profissionais na educação fundamental e média.

Manacorda (2007) afirma que o ensino técnico é adulterado pela burguesia, ao ensinar economia política e defender interesses da classe dominante. Ainda segundo Manacorda, para Marx deveriam ser criadas escolas politécnicas (união de ensino intelectual e trabalho físico e formação tecnológica), logo, mais uma vez, destaca-se a importância de perceber o elo teoria e prática na formação escolar. Para esclarecer o pensamento de Marx em qual deveria ser o papel social da escola, Manacorda (2007) diz que o conteúdo do ensino necessita ser pensado para além do contexto de divisão do trabalho e da educação burguesa, quando se trata da formação do trabalhador.

Marx considerava, na visão de Manacorda (2007), como conteúdo de ensino o conhecimento para formar o homem completo, omnilateral. Nessa busca, Marx revela nos Manuscritos de 1844 que o conhecimento não é apenas teoria de fácil explicação e sim está também nas atribuições da realidade, da vida real. Porém, é preciso não confundir o real com o empírico. No empírico reside o epiderme do real e as determinações são traços efetivos do movimento que constitui o real. Mesmo que não os conheçamos teoricamente, eles existem e operam.

Por conseguinte, parece clara a ideia de que para a escola agrícola ligar o aluno à classe construtora não basta agregar o trabalho à educação. Para chegar a completude dessa concepção de escola do trabalho, uma categoria é fundamental: a práxis. O PPP do Colégio Agrícola faz referência à práxis no sentido de que, se a atividade teórica, por conta própria não é capaz de modificar a realidade, afinal se concretiza sem a prática, também, a prática por si mesma, não é capaz de explicar a teoria; ambas são indissociáveis enquanto práxis. Assim, a ideia de práxis é reconhecer a latência presente no pensar. Ou seja, ela existe, porém é preciso que venha à tona, que não se conforme e continue latente na busca pelo "algo mais". Pode-se denominar de busca pela verdade a partir da reflexão; fazer o esforço de buscar a verdade a partir do existente e agir para transformar. Conforme Gramsci (1999, p.101), "uma filosofia da práxis só pode apresentar-se, inicialmente, em atitude polêmica e crítica, como superação da maneira de pensar precedente e do pensamento concreto existente (ou mundo cultural existente)".

Quer dizer, a teoria, que é a reflexão, mostra como funciona a realidade, e é preciso conhecê-la para não incorrer no erro da ingenuidade, no acreditar no "vale tudo" e agir cegamente. É preciso que teoria e prática partam da contradição, de forma crítica, consciente. Marx (1986), descreve a práxis enquanto revolucionária a partir do momento que ela reconhece a divisão de classes sociais quando o trabalho obedece ao mercado de capital. "A consciência de mudar as circunstâncias e da atividade humana só pode ser tomada e racionalmente entendida como práxis revolucionária” (MARX, 1986, p.12). Portanto, a educação que se quer emancipatória requer o entendimento da práxis política, cultural, crítica e reflexiva, princípios fundamentais de uma educação politécnica.

\section{A educação politécnica e algumas de suas experiências}

Para discutir educação politécnica, é preciso observar a história, quando, no meio do turbilhão de modificações resultantes da indústria moderna, Marx e Engels criticam de forma veemente a situação desgastante dos trabalhadores, "em especial das mulheres e crianças que eram transformados em meras máquinas capazes de fabricar mais-valia, excluídas as capacidades intelectuais" (MARX; ENGELS, 2004, p. 69). Marx e Engels percebem o despontar da indústria moderna com a maquinaria, a qual assume o primeiro lugar e o trabalhador/ser humano tendo seu grau de importância diminuído. A indústria do capital de posse da maquinaria passa a se apropriar dos conhecimentos necessários para o trabalho, aumentando vertiginosamente a produtividade.

Para contrapor-se ao processo de alienação do trabalhador, Marx e Engels propõem uma forma de educação voltada para a politecnia, gestada, não pelo burguês detentor dos meios de produção, mas sim sob a ótica de formação necessária ao trabalhador, ampliando o universo humano. A escola que Marx e Engels apontam como possibilidade de formação humana não é um lugar miserável, capaz de se fechar entre quatro paredes, funcionando mais como um lugar de acúmulo de crianças. Isso acontecia no início, nas primeiras escolas do século XIX, onde "o mobiliário escolar é pobre, há falta de livros e de material de ensino e uma atmosfera viciada e fétida exerce efeito deprimente sobre as infelizes crianças" (MARX; ENGELS, 2004, p. 70).

O estudo de Shulgin possibilitou a compreensão de que é possível uma escola 
diferente, não pensada somente para definir quem comanda ou quem é comandado. Questiona sobre a escola do campo: "mas, e o trabalho agrícola, a escola do campo? Como fazer com ela? Haveria algum passo na direção da escola do trabalho?" (SHULGIN, 2013, p.41).

O questionamento de Shulgin (2013) tenciona revelar se o trabalho agrícola, que é ensinado nas escolas do campo ou agrícolas, baseiase enquanto formação que capacita os alunos a refletir e interpretar a realidade e ainda compreender a organização do trabalho presente na sociedade por meio dessa formação. Existe a preocupação, e é externada por Shulgin ao questionar como proceder com a escola do trabalho agrícola, a investigá-la se vai em direção à escola do trabalho e não na contramão?

Shulgin (2013) não tem dúvidas de que a escola de trabalho agrícola insere o aluno no exercício do trabalho em si. Cumpre, portanto, com a objetividade do trabalho quando "liga" o aluno com a "classe-construtora" e não apenas explica o que é o trabalho. Porém, é pouco; o trabalho é mais que isso. Para ele, é o elementar da vida humana, logo o elementar da educação é perceber a atualidade no ato de ensinar.

Se considerar a educação do campo como recorte, um tema sob o qual não se tem clareza, os estudos são incipientes, portanto, mais difícil tornase a intenção, não menos instigante. Pereira (2012) ressalta a educação politécnica reivindicada pelos campesinos:

Une a tríade "campo, políticas públicas e educação" princípios como: o trabalho como princípio pedagógico - inspirado em Makarenko e Pistrak; o encontro com a educação politécnica; a técnica e a ciência como produtoras de tecnologias sociais; a cultura como princípio pedagógico; e a relação campocidade de modo crítico, ao pensar a totalidade da formação da classe trabalhadora brasileira (PEREIRA, 2012, p.291, grifo nosso).

A escola pensada para o campo pode ser um meio que vai auxiliar o processo tecnológico e coletivo do campo, entendendo a luta de classes e modificando as formas de gestão desse espaço. Muitas delas podem realizar ações práticas em contraposição aos pressupostos do capital no campo. Está posto um dilema para o Colégio Agrícola, pensar um projeto educativo que se declare e se efetive contra-hegemônico ao capital. Como muito bem aponta Caldart (2012, p. 38):
As formulações sobre a educação politécnica tendem a reforçar aspectos bem importantes para nossas práticas atuais: - a aproximação entre as reflexões sobre a produção e sobre projeto educativo; - a explicitação das contradições entre as tendências mais gerais do desenvolvimento do capitalismo no campo (projeto hegemônico que tende à subordinação e/ou destruição do campesinato) e as especificidades do campesinato e suas possibilidades de resistência e superação (construção de uma contra-hegemonia e emancipação).

Essa afirmação vem ao encontro do que pensa Saviani (2003), ao considerar que o entendimento de politecnia não passa pela fragmentação, nem diz respeito ao treinamento de determinadas partes de tarefas suficientes para o ingresso no mercado de trabalho enquanto proposta burguesa de politecnia. A educação politécnica passa necessariamente pelo conhecimento de como a produção moderna se organiza.

Nesse sentido, conceituar o termo politecnia envolve capacitação técnica e domínio científico. Por exemplo, não basta podar a figueira; é preciso saber como e quando fazê-la. Todavia, para poder compreender o mundo e transformá-lo, existe algo mais, sobretudo porque envolve o domínio político. A questão do poder político, da luta de classes, é uma proposta para o sujeito que trabalha com vistas a uma proposta socialista, significa, assim, trabalhar as mediações numa proposta de educação do futuro, politécnica.

Com o dirimir de algumas dúvidas, o caminho encontrado foi buscar na história experiências, tentativas, que ousaram um projeto educativo diferente, via contramão do capitalismo. Assim, acredita-se que a origem dessas experiências não coincide com a realidade atual, mas, para conhecê-la, é preciso conhecer os fenômenos históricos dos quais alguns elementos possam ter algumas relações. Sob tal perspectiva, algumas experiências de educação politécnica que aconteceram na República Soviética, Alemanha, em Cuba e no Brasil serão aqui relatadas.

$\mathrm{Na}$ República Soviética, Lunatcharski (1988) toma o conceito de politecnia como sinônimo de totalidade, ao argumentar que se o cenário econômico da época possibilitasse construir uma escola do trabalho e politécnica ao longo dos anos de estudos dos alunos, a politecnia poderia ser exercitada de forma aprofundada não somente como técnica. Também como capaz de formar para o 
mundo com uma concepção desse mundo construída paulatinamente com o conhecimento dos aspectos científicos e práticos.

Assim, o objetivo para a escola ser politécnica é diferente do aluno saber apenas o que é um trabalho científico/técnico organizado e sério e que, para tanto, basta sentir isso, ter uma ideia desse trabalho. Nessa concepção, se o aluno for iniciado em diversos processos técnicos, ele será, segundo Lunatcharski (1988), um pan-técnico, e não é isso que a educação politécnica significa.

Na Alemanha Oriental Market (1996) cita o pedagogo W. Kuhrt, que a educação politécnica como uma educação capaz de considerar e aproveitar as transformações da ciência, técnica, tecnologia, processos de produção e reprodução da indústria e da agricultura por meio da formação geral a partir do que é primordial e fundamental. A crítica ao princípio de formação politécnica na Alemanha Oriental, segundo Market (1996), inserese na base técnica da educação. Educação orientada pela técnica voltada para o desenvolvimento de forças produtivas do sujeito, não cabendo o ideal de educação integral para o trabalho, comungando com uma formação para o trabalho assalariado, haja vista que o Estado alemão centralizou todas as ações tanto econômicas quanto pedagógicas do trabalho.

Villela (2011) relata a experiência das escolas no campo em Cuba, entre 1960 e 1975, de ideal politécnico eram caracterizadas como escolas agrícolas e estavam destinadas ao plantio e à colheita, observadas todas suas etapas, desde a preparação do solo até o destino final de cítricos, café, tabaco, tubérculos, grãos e vegetais em conformidade com as capacidades de cada aluno.

Cada escola alocaria em torno de 500 hectares de terra cultivável, que seriam utilizadas pelos alunos durante uma sessão de três horas por dia. Esta sessão de trabalho seria alternada com a sessão de cinco horas de docência e várias atividades esportivas e culturais. O número de matriculas de cada escola seria de 600 alunos, todos internos e geralmente provenientes de regiões vizinhas (TOGORES, 1979 apud VILLELA, 2011, p. 9). ${ }^{3}$

Observa-se que este "formato" de escola lembra os Colégios Agrícolas em sua estruturação física e pedagógica, já que possuem terras chamadas de Unidades Didático Produtiva ou Fazenda Escola e que são cultivadas quando os alunos praticam a teoria nas aulas práticas. O estudo também se alterna com as atividades desportivas e culturais.
No Brasil, Saviani (1989), no livro que discute a concepção de politecnia, aponta a Escola Politécnica de Saúde Joaquim Venâncio, da Fundação Oswaldo Cruz, criada no final de 1985, como tendo suas ações pautadas na perspectiva de uma formação politécnica. Objetiva assegurar ao sujeito a aprendizagem dos conhecimentos técnicooperacionais, bem como os fundamentos científicos e filosóficos que orientam determinada modalidade de trabalho.O projeto educativo preocupa-se em discutir o método capaz de tornar a formação politécnica sinônimo de formação humana.

Pergher (2012), apresenta o Instituto de Educação Josué de Castro em Veranópolis/RS, analisa que o Instituto toma a pedagogia do MST Movimento dos Trabalhadores Sem Terra e a relaciona com as práticas sociais formativas da escola, tanto na organização, quanto no trabalho pedagógico, auxiliando na formação crítica e que transpassa a intenção de formação unilateral burguesa.No Instituto,o trabalho é o princípio educativo e a formação profissional não se sobrepõe à formação humana.Em sua organização educativa estão definidos tempos educativos que envolvem os alunos, alguns deles também se apresentam no Colégio Agrícola, como a auto-organização, o autosserviço e o trabalho. Contudo, o Instituto visa educar para o socialismo, como um princípio comum ao MST.

Destaca Pereira (2012) uma terceira: Escola Agrícola 25 de Maio, fundada em 1989, em área de assentamento de Reforma Agrária, Vitória da Conquista em Fraiburgo/SC, com curso técnico em Agropecuária com ênfase em Agroecologia. "O referido curso prioriza a coletividade, a autonomia e a emancipação camponesa diante do modelo agroindustrial instalado no campo brasileiro" (PEREIRA, 2012, p.293). Justamente por serem grupos distintos, Freitas (2011) reforça a importância dos professores técnicos que defendem uma formação ampla e buscam a possibilidade a partir das contradições de construir um projeto educativo resistente, fortificado a partir dos conflitos.

Os apontamentos, conceituações e exemplos de projetos de educação tratados e discutidos até aqui demonstram que existe uma estrutura que está posta (divisão do trabalho, políticas públicas de educação, relações sociais...), organicamente vinculada à superestrutura com seus organismos e ideologias (diferentes instituições sociais). Assim, a educação está localizada bem no meio desse emaranhado, não sendo possível negar seu 
envolvimento, o que torna fundamental discutir a que se destina, com que intencionalidade planeja e executa seu projeto educativo. A ideia central da discussão das experiências e do conceito de politecnia trouxe, a nosso ver, uma melhor aproximação com o objeto de pesquisa, o que significa dizer que são apontados alguns elementos no transcorrer do texto que têm relação com a educação do Colégio Agrícola.

\section{As práticas pedagógicas do Colégio Agrícola e a educação politécnica}

A relação ente o ensino e o trabalho no Colégio Agrícola é um elemento de suas práticas pedagógicas que não passa sem ser notado. Nesta instituição de ensino público, constatar alunos estudando e trabalhando é constante, pois nela ocorre relação estreita entre ensino e trabalho, teoria e prática. Ao constatar alunos em uma determinada propriedade podando árvores, de pronto identificase que existe uma organização diferenciada na prática pedagógica do Colégio. Dificilmente se observa instituições educativas que não tenham como organização central a sala de aula, que se apresenta como uma espécie de isolamento, de "esconderijo" do meio.

Freitas (2009) cita Pistrak, ao referir que a escola capitalista definiu que a formação dos jovens aconteceria imprescindivelmente em salas de aula, como um instrumento capaz de bloquear o contato com a vida e suas contradições. Para Freitas, Pistrak acreditava que era de fundamental importância abrir as portas da escola para a vida latente, fora do contexto de sala de aula.

A questão de aproximar com a realidade e suas contradições, perceber o que existe de atual, novas técnicas, poder aplicá-las na propriedade e na escola cria o interesse no aluno, talvez por essa razão, tantos alunos buscam estudar no Colégio Agrícola. Fazer parte do processo e ver o resultado prático da teoria, aos poucos os fundamentos do trabalho são entendidos e passam a fazer parte de sua organização pessoal. Para fazer parte do processo, o Colégio Agrícola propicia ao aluno, além das demais práticas, o estágio supervisionado.

O Estágio Supervisionado em propriedade é um tempo de convívio e reflexão, pois os alunos passam a conviver com a família do produtor. Nesse sentido, além de perceber todos os dados técnicos e atividades desenvolvidas diariamente, também se efetiva o relacionamento entre o estagiário e a família. Destaque para a prática do estágio, enquanto elemento de busca da práxis, no sentido de poder experimentar a teoria, verificar se na prática realmente ela se fundamenta, voltar para a teoria depois de ter sentido o que funciona ou não, retomar a teoria, refazê-la.

Demonstra o movimento que o estágio permite ao interpretar os acontecimentos, refletir sobre, viver o estágio e perceber de onde se origina o trabalho e sua importância para a realidade humana, são aspectos manuais e intelectuais voltados à noção de politecnia. Após a realização do estágio, vem a confecção do relatório, a apresentação, a troca de ideias e discussão com a turma e com os professores, acontece todo um processo que auxilia na compreensão da totalidade de sua profissão.

As "Monitorias" visam sempre o coletivo, é um espaço coletivo, público e não individual, esse é um princípio que não pode ser descartado e sim avaliado e levado em consideração quando o assunto é educação politécnica. Ou seja, o coletivo é um fundante da educação politécnica. A partir disso é possível refletir, observar que, enquanto um aluno está comendo, tem um colega lavando a sua louça, sabendo que na semana anterior ou na seguinte foi/será a sua vez. Para Pistrak (2015, p.172):

A educação para o trabalho deve começar com o trabalho cotidiano, de autosserviço. Para que o estudante seja conduzido às mais altas formas de trabalho industrial, é preciso passar ele mesmo por um determinado período de acumulação de grande variedade de habilidades de trabalho; é preciso começar a partir daqueles com os quais ele se encontra na vida cotidiana.

Em relação aos trabalhos pessoais, trabalho do dia a dia, o autosserviço enquanto trabalho educativo, é capaz de criar novos valores nos alunos que são importantes para sua formação enquanto coletividade e que retornam para a sociedade. Para Ritter, Grein e Solda (2015, p. 134), o autosserviço também contribui

[...] na compreensão de que para viver há algumas tarefas indispensáveis, as quais não são responsabilidade de um gênero específico, de uma determinada função, de um funcionário, mas de todo um coletivo que vive naquele ambiente. O autosserviço estabelece, desta forma, que meninos e meninas têm a mesma capacidade e que juntos podem se desenvolver e aprender.

Nas atividades de autosserviço não 
acontecem diferenciações entre alunos do gênero feminino e masculino, já que essas atividades são realizadas por ambos, mais um aspecto a ser ressaltado como possibilidade de educação politécnica. Do simples para o complexo, existe um caminho que se constrói aos poucos e se complementa com práticas diferenciadas que formam também o humano, para a totalidade.

Os "Grupos de Estudo" são realizados no período noturno por cada turma e consiste em grupos de 04 a 05 alunos. Um dos alunos é escolhido para ser o monitor de cada grupo que irá desenvolver ações como: organizar os trabalhos e tarefas durante os estudos em equipe, auxiliar os colegas nas dúvidas, ser mediador das discussões em equipes. Para Gramsci (1991, p.121), "é útil uma certa 'estratificação' das capacidades e hábitos, bem como a formação de grupos de trabalho sob a direção dos mais aptos e desenvolvidos, que aceleram a preparação dos mais atrasados e toscos".

É uma atividade escolar que forma o hábito de estudos nos alunos, como mesmo aponta Gramsci (1991, p.133): "um estudioso de quarenta anos seria capaz de passar dezesseis horas seguidas numa mesa de trabalho se, desde menino, não tivesse assumido, por meio da coação mecânica, os hábitos psicofísicos apropriados". $\mathrm{Na}$ visão de Gramsci é necessário que a escola seja pressionada para criar hábitos psicofísicos apropriados. Isso no sentido de conseguir que aflorem estudiosos necessários à formação da humanidade. Liga-se, então, o estudar ao futuro ato do trabalho na vida adulta, já que o estudo também é encarado por Gramsci (1991) como um trabalho exaustivo:

Deve-se convencer a muita gente que o estudo é também um trabalho, e muito fatigante, com um tirocínio particular próprio, não só muscularnervoso, mas intelectual: é um processo de adaptação, é um hábito adquirido com esforço, aborrecimento e mesmo sofrimento (GRAMSCI, 1991, p.138).

Aqui toca-se no ponto considerado mais importante quando o assunto é educação politécnica, ou seja, o hábito de organizar-se para o estudo, que a prática dos Grupos de Estudo pressupõe aos alunos, leva a uma prática essencial da educação politécnica: a auto-organização coletiva.Aos poucos o aluno vai amadurecendo e se auto-organizando.

Com a auto-organização proporcionada pelas práticas pedagógicas, inclusive pelos grupos de estudos, é possível pensar no trabalho enquanto educativo, seja o trabalho produtivo ligado ao campo, de manutenção e higiene ligado ao internato, e o trabalho social ligado à comunidade, principalmente aprendendo a se organizar para os estudos.

Além de se organizar para os estudos, outras atividades como a Semana de Estudos Agropecuários e Qualidade de Vida (SEAGRIL) também passa por um longo caminho de organização. É uma semana gestada durante vários meses, e tem início com a organização pedagógica das atividades e temas de trabalho que serão eleitos durante a semana de estudos. Todo o trabalho de organização é realizado por reuniões, contatos com instituições e profissionais, divisão de tarefas. São muitos temas, oficinas, visitas técnicas, seminários, apresentações, entre outros.

A intencionalidade de se trabalhar nesse formato pedagógico, a partir das participações ativas na decisão dos temas, também se justifica para que alcem relação mais permanente com o contexto sociocultural em que eles vivem. Para Fagiani et al. (2013, p. 216):

Portanto, a formação de sujeitos sociais plenos, bem como os objetivos da educação em seu sentido social, político e pedagógico de formação para a cidadania tornam-se restritos às necessidades imediatas de qualificação profissional impostas pelo mercado de trabalho.

Nesse sentido, a SEAGRIL é uma expressão do mundo real dos alunos, e vai além deste, da formação restrita ao mercado de trabalho, ao propor os seus temas acerca da economia local e mundial. Tem como um de seus momentos importantes a elaboração e apresentação da síntese e das oficinas pelos alunos, de tudo o que aconteceu durante o período de sua realização. Assim, os alunos, para cada atividade realizada, fazem uma síntese ou uma apresentação no caso das oficinas com os principais pontos, a partir de um roteiro préelaborado por professores e equipe pedagógica. Com o término da semana de estudos, o objeto passa a ser sintetizado, é o caminho de volta, em que a teoria passou pela prática e retornou para a teoria.

Uma atividade que está presente no contexto em que os alunos do Colégio Agrícola vivem, é a prática pedagógica nominada pelo PPP (2012) de Dia de Campo Agropecuário, que ganha novo significado a partir da elaboração dos professores, principalmente os da Área Técnica que o planejam. É organizado de forma que, durante o 
primeiro semestre, os professores trabalham, nas aulas teóricas e práticas, conteúdos relacionados às produções agrícolas das variedades de inverno e de verão. O objetivo dos "Dias de Campo", desenvolvidos na Fazenda Escola, segundo o PPP (2012), é apresentar à comunidade trabalhos e experiências realizadas pelos alunos e professores durante o ano letivo. No "Dia de Campo" participam todos os alunos, professores $\mathrm{e}$ funcionários do Colégio e é uma atividade da qual toda a comunidade pode participar.

O "Dia de Campo" é considerado sob o ponto de vista do agronegócio como uma estratégia de marketing. Santos (2011, p.56) reforça esse compreensão ao considerar que, para "dobrar" o homem rústico do campo, foram utilizadas "estratégias bem conhecidas como os dia de campo, show rural, exposição agropecuária, festas de municípios, entre outros". Porém, no Colégio Agrícola "Dia de Campo" é visto como uma prática pedagógica, pois envolve muita pesquisa, conhecimento, planejamento, organização e integração das disciplinas.

Para Shulgin (2013, p. 181), “[...] e, se quiserem falar sobre a escola politécnica, busquem as suas premissas aqui, nestes pedaços do futuro, na atualidade", com a relação educação e trabalho ligase o jovem ao mundo atual, ao meio social, aos conceitos e categorias. Para tanto, é necessária uma metodologia voltada para a atualidade, a vida diária com todos seus conflitos e contradições.

O Colégio Agrícola tem desenvolvido ao longo de toda sua constituição "Práticas de Projetos Especiais", mas não são simples projetos. Nessas práticas são desenvolvidas atividades de implantação de culturas, manutenção, plantio, tratos culturais, colheita e organização desenvolvimento e avaliação de experimentos, com acompanhamento dos resultados técnicos. As atividades são planejadas pelos professores da Área Técnica em sua maioria, porém, os professores da Base Nacional Comum também participam. Shulgin (2013) destaca duas definições para trabalho social: $1^{\mathrm{a}}$ - tipo de trabalho que produz algum resultado plenamente real, concreto; e $2^{\mathrm{a}}$ - trabalho que tem valor pedagógico.

Como exemplo, relata-se uma prática realizada no final do ano de 2015 , em conjunto com o Departamento de Assistência Social da Prefeitura Municipal de Francisco Beltrão, Universidade Paranaense- UNIPAR e Colégio Agrícola. Foram os alunos dos terceiros anos que participaram e realizaram a prática de paisagismo, conteúdo de disciplina da Área Técnica.

Nesse sentido, entende-se que trabalho socialmente realizado pela escola em conjunto com outras instituições também é ganho para as condições de vida da comunidade local, aqui no caso, moradores do Programa Minha Casa, Minha Vida do Governo Federal.

Pistrak (2015), ao se referir ao trabalho social, reforça que não deve acontecer casualmente; é preciso ter habilidade, não reduzida e sim ampliada. Em outras palavras é preciso saber o que se está fazendo, estabelecer propósito e cumpri-las, planejar, discutir a questão. Pistrak propõe etapas para a execução do trabalho: objetivo, plano, campanha pela implementação do plano, processo real de implementação e avaliação, o que sugere a verificação se estas etapas ocorrem no trabalho realizado.

Uma questão é pertinente: será que tal atividade é mesmo capaz de desenvolver o aluno do Curso Técnico em Agropecuária de maneira multilateral? Não foi apenas mais uma metodologia de ensino, somente para que os alunos assimilassem os conteúdos?

Definida com mais propriedade a atividade, observa-se claramente o caráter pedagógico, social, político do projeto. É possível considerar que essa não foi uma atividade somente para assimilar os conteúdos das disciplinas ante à práxis que resultou de sua execução. Também não foi do livro para a vida - aqui no caso do projeto - e sim partiu do contexto, ou seja, do social. Se essa for uma prática levada a efeito como aponta a pedagoga 07, e todas as etapas já citadas forem respeitadas (objetivo, plano, campanha pela implementação, processo real de implementação e avaliação), terá o Colégio Agrícola exercitado também a autonomia e autoorganização dos alunos, consequência do trabalho socialmente necessário.

Constitui-se numa tarefa fácil? Com certeza não, principalmente em escolas que têm a sala de aula como centralidade. Porém, esta é passível de realização, pois, conforme Pistrak (2003, p.104),

Introduzir desta forma os elementos da organização científica do trabalho na escola é uma tarefa difícil, porque a organização científica do trabalho não está ainda difundida, e também porque nós mesmos não formamos o pessoal e não concebemos o trabalho com base na organização científica do trabalho, por falta de hábitos, gosto e conhecimentos necessários.

Por mais distante que esteja o tempo em que 
foi escrita, essa reflexão é atual, ou seja, geralmente os profissionais envolvidos com educação não apresentam intenção ou o hábito de pensar a organização da escola. Existem situações em que, nem mesmo a comunidade ou entorno da escola, é conhecido pelo profissional que ali atua.

\section{Considerações Finais}

Num primeiro momento, parece mesmo ingenuidade acreditar que um Colégio Agrícola que, a princípio, foi pensado para formar mão de obra voltada ao agronegócio, poderia desenvolver uma proposta de educação a partir dos princípios formativos da politecnia. Saber resistir ao mercado é a grande questão que divide atitudes e opiniões. As possibilidades de apropriar-se das teorias a partir do contexto, da prática social, são muitas e estão presente em todo momento quando na condição das inquietações pedagógicas.

A questão do desenvolvimento científico e tecnológico é uma realidade para os agricultores familiares do Sudoeste do Paraná, visto que estes alcançam políticas públicas para o campo. Todavia, ocorre a apropriação desse desenvolvimento, mas sem a devida capacidade de ler o campo de maneira crítica e perceber os processos capitalistas envolvidos de divisão desigual dos bens econômicos e sociais. Eis aí uma questão para que o Colégio Agrícola, ao ousar construir uma educação politécnica, necessita enfrentar para tornar os alunos capazes de refletir e interpretar a realidade, bem como compreender a organização do trabalho presente na sociedade e divisão desigual daqueles bens.

Frente à história que se revelou ao longo da pesquisa, ficou claro como o Colégio Agrícola não constituiu em seu projeto educativo elementos das bandeiras de luta que o concretizaram. Somam-se diversas potencialidades educativas de grande valor no Colégio Agrícola. Vão desde a luta social para manter-se como instituição escolar, o trabalho de autosserviço que desvincula o jovem do individualismo vantajoso e traz a compreensão do coletivo como forma de respeito e educação, e um espaço que compreende o eu e o outro, além de preparar as bases para o trabalho que realizará amanhã.

Ao seguir os passos propostos por Shulgin (2013) e Pistrak (2015), buscou-se demonstrar como o trabalho socialmente necessário pode ser realizado nas escolas. Trabalho que tira o aluno do isolamento da sala de aula e coloca-o diretamente em contato com a atualidade. Mas é um caminho complexo de inserir o jovem do campo na condição de trabalhador politécnico, no sentido de compreender as relações de trabalho que permeiam a sociedade, tanto no campo quanto na cidade, e qual sua condição nesse contexto. Ainda, de poder elevar-se à cultura humana historicamente produzida, ser político no sentido da coletividade, além de ter capacidade científica e técnica para apropriar dos conhecimentos e das tecnologias disponíveis.

A educação de Ensino Médio e Profissional do Colégio Agrícola está organizada na associação entre estudo e trabalho. O ensino estabelecido na relação teoria e prática, as vivências dos Estágios Supervisionados, Visitas Técnicas e Aulas Práticas, os Dias de Campo, Semana de Estudos Agropecuários, Grupos de Estudo, o tempo escolar de Internato e as Monitorias são práticas pedagógicas pelas quais essa educação se caracteriza.

Nesse sentido, essas considerações finais apontam para diversas potencialidades educativas no Colégio Agrícola. Remetem-se às ações sociais de sua manutenção como instituição de Ensino Médio, às práticas que educam com o trabalho. Todas práticas que, aos poucos, envolvem e tornam os alunos capazes de auto-organização, fator que implica diretamente no processo de educação.

\section{Notas}

1 O agente "Instrutor" é o mediador do conhecimento e da prática profissional junto aos participantes dos eventos. São profissionais multidisciplinares, como agrônomos, veterinários, zootecnistas, técnicos agrícolas, artesãos, profissionais da saúde, etc., que são selecionados por cada Administração Regional e passam por um processo de cadastramento, credenciamento, formação e supervisão. Cada AR divulga as informações sobre os processos seletivos de forma específica e em seus sites ou meios de comunicação com a Sociedade (SENAR, 2015).

$2 \mathrm{O}$ empreendedor rural aborda e trabalha a gestão da propriedade rural e o empreendedorismo das pessoas do meio rural. Estimula o debate e a formação de lideranças. Ensina a calcular custos do processo produtivo e a elaborar projetos para que os produtores rurais passem a administrar suas propriedades com eficiência, como se fossem verdadeiras empresas (SENAR, 2015).

3 A cada escuela se asignaría algo más de 500 hectáre as de tierra cultivable, que sería atendida 
por los alumnos durante uma sesión de tres horas al día. Esta sesión de trabajo se alternaria com La sesión de cinco horas de docência y diversas actividades deportivas y culturales. La matrícula de cada escuela sería de 600 alumnos, todos internos y que provenían, en general, de regiones vecinas (TOGORES apud VILELLA, 2011, p.9).

\section{Referências}

CALDART, R. Relatório-Síntese do Seminário: educação politécnica e agricultura camponesa. Veranópolis/RS: IEJC, 2012.

CIAVATTA, M. O conhecimento histórico e o problema teórico-metodológico das mediações. In: FRIGOTTO, G; CIAVATTA, M. (Orgs). Teoria e Educação no Labirinto do Capital. 2 ed. . Petrópolis, RJ: Vozes, 2001.

D'AGOSTINI, A.; VENDRAMINI, C. R. Educação do campo ou educação da classe trabalhadora? A perspectiva do empresariado, do estado e dos movimentos sociais organizados. Revista Reflexão e Ação, Santa Cruz do Sul, v.22, n.2, jul./dez. p.299322, 2014.

FAGIANI, C. C; PREVITALI, F. S; LUCENA, C; FRANÇA, R. L. Trabalho e Educação Profissional no Brasil: Formação humana ou para o mercado? In: BATISTA, E. L; MÜLLER, M. T. (Orgs). A Educação Profissional no Brasil: história, desafios e perspectivas para o Século XXI.1 ed. Campinas, SP: Alínea, 2013, p.203-218.

FREITAS, H. C. de A. O curso técnico em agropecuária da Escola 25 de Maio: conflitos em torno da construção da proposta agroecológica. Revista Brasileira de Agroecologia. Brasília, p.1329, 2011.

FREITAS, L. C. de. Currículo, trabalho e escola contemporânea. (A luta por uma pedagogia do meio: revisitando o conceito). In: PISTRAK, Mosey Mikhaylovich (Org.). A comuna escolar. Trad. Luiz Carlos de Freitas e Alexandra Marenich.1 ed. São Paulo: Expressão Popular, 2009. p.9-103.

GOODSON, I.. F.Currículo: Teoria e história. 4 ed. . Petrópolis, RJ: Vozes, 1995
GRAMSCI, A. Os intelectuais e a organização da cultura. 8 ed, . São Paulo: Civilização Brasileira, 1991.

Cadernos do cárcere. Vol. 1. 1 ed. . Rio de Janeiro: Civilização Brasileira, 1999.

LUNATCHARSKI, A. Sobre a Instrução $e$ a Educação. 1 ed. . Tradução de Filipe Guerra. Tradução para o português Edições Progresso, 1988.

MANACORDA, M. A. Marx e a pedagogia moderna 1 ed..Trad. Newton Ramos de Oliveira. Campinas, SP: Editora Alínea, 2007.

MARX, K; ENGELS, F.Textos sobre educação e ensino. Karl Marx e Frederich Engels. Tradução de Rubens Eduardo Frias. 4 ed. São Paulo: Centauro, 2004, p.67-87

MARX, K.Teses sobre Feuerbach. In: MARX, K; ENGELS, F. A ideologia alemã.São Paulo: Ciências Humanas, 1986.

MARKET, W. Trabalho, qualificação e politecnia. 1 ed. . Campinas, SP: Papirus, 1996. (Coleção Educação e transformação)

PARANÁ, CEE. Deliberação 09/2006 - Normas Complementares às Diretrizes Curriculares Nacionais da Educação Profissional Técnica de Nível Médio e de Especialização Técnica de Nível Médio. 20/12/2006.

PEREIRA, I. B. Educação Profissional. In: CALDART, R. S; PEREIRA, I. B; ALENTEJANO, P; FRIGOTTO, G. (Orgs). Dicionário da Educação do Campo. São Paulo: Escola Politécnica de Saúde Joaquim Venâncio, Expressão Popular, 2012, p. 286-293.

PERGHER, E. G. A escola do trabalho: um estudo no Instituto de Educação Josué de Castro. 2012. 158 f. Dissertação de mestrado - Universidade Federal do Rio Grande do Sul, Faculdade de Educação, Programa de Pós-Graduação em Educação. Porto Alegre: $\quad$ RS, 2012. Disponível em:http://www.lume.ufrgs.br/handle/10183/61749. Acesso em: 01/06/2015.

PISTRAK, M. M. Ensaio sobre a escola politécnica. 1 ed. São Paulo: Expressão Popular, 2015. 
. Fundamentos da escola do trabalho. 3 ed. São Paulo: Expressão Popular, 2003.

PLANO DE CURSO. Centro Estadual de Educação Profissional do Sudoeste do Paraná. Secretaria de Estado da Educação. Francisco Beltrão/PR, 2011.

PROJETO POLÍTICO PEDAGÓGICO. Centro Estadual de Educação Profissional do Sudoeste do Paraná. Secretaria de Estado da Educação. Francisco Beltrão/PR, 2012.

RITTER, J; GREIN, M. I; SOLDA, M. A questão do trabalho na Escola Itinerante. In: SAPELLI, M, L. S; FREITAS, L. C. de; CALDART, R. S. (Orgs.). Caminhos para transformação da escola: organização do trabalho pedagógico nas escolas do campo: ensaio sobre complexos de estudo. 1 ed. São Paulo: Expressão Popular, 2015.

SACRISTÁN, J. G. O currículo: uma reflexão sobre a prática, 3 ed, POA/RS: ArtMed, 2000.

SANTOS, J. C. Jecas Pós-Modernos: saberes, tecnologia e suicídio. In: VANDERLINDE, $\mathrm{T}$. (org.) Fronteiras: impactos socioambientais na terra prometida. POA/RS: Evangrof, 2011.

SAVIANI, D. O choque teórico da politecnia. Revista Trabalho, educação e saúde. Rio de Janeiro. v.1, p.131-152 n.1 mar 2003.

Sobre a concepção de politecnia. 1 ed.
Rio de Janeiro: FIOCRUZ. Politécnico da Saúde Joaquim Venâncio, 1989.

SENAR-Serviço Nacional de Aprendizagem Rural. Disponível em: http://www.senar.org.br/programa/programaempreendedor-rural; Instrutores. Acesso em 15 nov. 2015.

SHULGIN, V. N. V. Rumo ao politecnismo (artigos e conferências). 1 ed. São Paulo: Expressão Popular, 2013.

SILVA, C. E. M. Desenvolvimento Sustentável. In: CALDART, R. S; PEREIRA, I. B; ALENTEJANO, P; FRIGOTTO, G. (Orgs.) Dicionário da Educação do Campo. São Paulo: Escola Politécnica de Saúde Joaquim Venâncio, Expressão Popular, 2012.

SOUZA, R. F. História da organização do trabalho escolar e do currículo no século XX: (ensino primário e secundário no Brasil). 1 ed. . São Paulo: Cortez, 2008. (Biblioteca básica da história da educação brasileira, v.2).

VILLELA, F. F. As práticas educativas em educação do campo e os desafios da formação omnilateral na América Latina. Revista NERA, ano 14, no 19, , p 90-103 , jul-dez/2011.

Disponível

em:file:///C:/Users/Usuario/Downloads/Praticas_ed ucativas_comparadas_em_educacao_do_campo $\% 20$ (1).pdf. Acesso em:03/04/ 2015.

\section{Sobre os autores}

Nara Tatiana Costa: Pedagoga da Rede Estadual de Educação do Paraná, com atuação em Francisco Beltrão/PR. Mestra em Educação pela Unioeste, Campus de Francisco Beltrão/PR.

Clésio Acilino Antônio: Professor Adjunto da Unioeste, Campus de Francisco Beltrão/PR. Docente nos cursos de Curso de Pedagogia e Mestrado em Educação. Doutor em Educação.

Submetido em outubro de 2016.

Aprovado em fevereiro de 2018. 